\title{
Pattern of Non-Communicable Diseases among the Admitted Patients in a District Level Hospital of Bangladesh
}

\author{
Md. Mahfuzur Rahman ${ }^{1}$, Muhammad Anwarul Kabir², Maria Mehjabin ${ }^{3}$
}

\begin{abstract}
Background: Non-communicable Diseases (NCD), particularly cardiovascular diseases, cancer, diabetes and chronic respiratory disease, have emerged as the leading threat to mankind worldwide. Likewise in Bangladesh, an increasing trend of incidence of NCDs has been observed and already they have become major public health concern. Hence, we aimed to study the pattern of NCDs among the admitted patients at an Upazila Health Complex (UHC) in Bangladesh.

Methods: In this retrospective study, data of in-hospital patients admitted from January 2018 to June 2018 in UHC, Chhagalnaiya, Feni was analyzed. Data on age, gender, occupation, hospital admission/discharge and diagnosis of disease was obtained from the hospital register. Diseases were categorized into NCD or communicable disease using the World Health Organization's International Classification of Diseases (ICD) coding system.
\end{abstract}

Results: 1,367 adult patients with different diseases were admitted into the medical ward over the study period of six months (mean age $57.4 \pm 17.9$ years; $61.3 \%$ male and $38.7 \%$ female). There were 904 cases of various NCDs constituting $66.1 \%$ of total admissions. The number of cases of NCDs was two times more compared to CDs (ratio 2:1). In all six months, admissions due to NCDs were significantly higher compared to communicable diseases CDs ( $p=0.0001)$. Among the admissions due to NCDs, more than half $(51.3 \%)$ were aged between 50 to 69 years. In terms of pattern of disease, cardiovascular diseases were the number one cause for hospital admission followed by endocrine disorders.

Conclusion: This study found that the burden of NCDs has increased among the admitted patients in an UHC. These findings could be useful to draw the attention of health authorities to adopt preventive strategies against NCDs even at Upazila level.

Keywords: Non-communicable Diseases, Upazila Health Complex, Bangladesh.

(Bangladesh Heart Journal 2019; 34(2): 118-121)

Introduction:

Non-communicable diseases (NCDs) are considered as the leading cause of morbidity and mortality globally ${ }^{1}$.

1. Assistant Professor, Dept. of Cardiology, Abdul Malek Ukil Medical College, Noakhali, Bangladesh.

2. Junior Consultant (Medicine), Upazila Health Complex, Chhagalnaiya, Feni, Bangladesh.

3. Post Graduate Fellow, Bangladesh College of Physicians \& Surgeon, Dhaka, Bangladesh.

Address of Correspondence: Dr. Md. Mahfuzur Rahman, Assistant Professor, Dept. of Cardiology, Abdul Malek Ukil Medical College, Noakhali , Bangladesh. Email: msbrahman165@yahoo.com, Phone: +88 01911627127
It is estimated that 40 million people die in each year because of NCDs, approximating $70 \%$ of all deaths worldwide. Among the NCDs, cardiovascular diseases account for 17.7 million deaths annually, followed by cancers (8.8 million), chronic respiratory diseases (3.9 million), and diabetes (1.6 million). These four groups of diseases account for over $80 \%$ of all premature NCD deaths ${ }^{2}$

The epidemic of NCDs poses catastrophic health consequences for individuals, families and

DOI: https://doi.org/10.3329/bhj.v34i2.44442

Copyright $\odot 2017$ Bangladesh Cardiac Society. Published by Bangladesh Cardiac Society. This is an Open Access articles published under the Creative Commons Attribution-NonCommercial 4.0 International License (CC BY-NC). This license permits use, distribution and reproduction in any medium, provided the original work is properly cited and is not used for commercial purposes. 
communities, and threatens to triumph over health systems. The economic burdens associated with NCDs make the prevention and control of these diseases a major development issue for the 21st century. Most of these premature deaths from NCDs are attributed to modifiable behavioral risk factors like tobacco use, unhealthy diet, physical inactivity and harmful use of alcohol, and metabolic risk factors like raised blood pressure, overweight/obesity, hyperglycemia and hyperlipidemia are also attributed to NCDs ${ }^{1}$.

Burden of NCDs and its mortality is observed to be more in lower and middle income countries. Available data demonstrate that nearly $80 \%$ of deaths due to NCDs occur in low and middle income countries ${ }^{2}$. In recent years, an epidemiological shift in morbidity and mortality from infectious diseases or malnutrition to NCDs has occurred in many low and middle income countries, including Bangladesh. NCDs, particularly cardiovascular diseases, cancer, diabetes, and chronic respiratory disease have already become major public health concern in Bangladesh ${ }^{3}$. Both NCDs and their risk factors are showing an increasing trend. These risk factors are tobacco use, low intake of fruits and vegetables, physical inactivity, obesity, raised blood pressure, and raised blood glucose and cholesterol ${ }^{3}$. Evidence shows that the detection and treatment rate of diabetes mellitus and hypertension is also inadequate among Bangladeshi population ${ }^{4,5}$. Most important fact is that NCDs and their risk factors are prevalent in both urban and rural areas of Bangladesh ${ }^{6}$.

Considering the increasing burden of NCDs in Bangladesh, this is the high time to adopt preventing strategies. In this regard, the data on NCDs are very important. However, only limited data are available limited from tertiary level hospitals. Hence, we aimed to study the pattern of NCDs among the admitted patients at an Upazila Health Complex (UHC) in Bangladesh.

\section{Methods:}

This is a retrospective study. The data of in-hospital patients admitted from $1^{\text {st }}$ January 2018 to $30^{\text {th }}$ June 2018 in UHC of Chhagalnaiya was analyzed. This UHC mainly caters the patients from Chhagalnaiya and surrounding areas. Chhagalnaiya is an Upazila of Feni District in the Division of Chittagong. It has a population of 170,524 (males $49.79 \%$ and females $50.21 \%$ ).

All patients aged more than 18 years of both sexes admitted during this period were included. Children and adolescence patients aged $<18$ years were excluded. Data on age, gender, occupation, hospital admission/ discharge and diagnosis of disease was obtained from the hospital register. Diseases were categorized into NCD or communicable disease (CD) using the World Health Organization's International Classification of Diseases (ICD) coding system.

There were two objectives of this study - to find out the ratio between NCDs and communicable diseases (CDs) and to study the pattern of NCDs. All analyses were done using Statistical Package for the Social Sciences (SPSS) software version 18 (Chicago, IL, USA). Comparison of variables was performed using the two-tailed paired $t-$ test. $p<0.05$ was considered statistically significant.

\section{Results:}

1,367 adult patients with different diseases were admitted into the medical ward over the study period of six months. The mean age of the admitted patients was $57.4 \pm 17.9$ years. Percentage of male patient was more compared to female patients ( $61.3 \%$ male and $38.7 \%$ female).

During the study period, there were 904 cases of various NCDs constituting $66.1 \%$ of total admissions. The number of cases of NCDs was two times more compared to CDs (ratio 2:1). The ratio was the highest in February. In all six months, admissions due to NCDs were significantly higher compared to CDs $(p=0.0001)$. The total result is summarized in Table-I and presented in Figure-1.

Table-I

Admissions due to non-communicable and communicable diseases

\begin{tabular}{|c|c|c|c|c|c|c|}
\hline \multirow[t]{2}{*}{ Month } & \multicolumn{2}{|c|}{ NCDs } & \multicolumn{2}{|c|}{ CDs } & \multirow{2}{*}{$\begin{array}{c}\text { Total } \\
\text { admissions }\end{array}$} & \multirow{2}{*}{$\begin{array}{c}\text { NCD/CD } \\
\text { Ratio }\end{array}$} \\
\hline & $\mathrm{n}$ & $\%$ & $\mathrm{n}$ & $\%$ & & \\
\hline January & 130 & $66.0 \%$ & 67 & $34.0 \%$ & 197 & 1.9 \\
\hline February & 118 & $69.0 \%$ & 53 & $31.0 \%$ & 171 & 2.2 \\
\hline March & 131 & $62.4 \%$ & 79 & $37.6 \%$ & 210 & 1.7 \\
\hline April & 173 & $66.0 \%$ & 89 & $34.0 \%$ & 262 & 1.9 \\
\hline May & 190 & $67.4 \%$ & 92 & $32.6 \%$ & 282 & 2.1 \\
\hline June & 162 & $66.1 \%$ & 83 & $33.9 \%$ & 245 & 2.0 \\
\hline Total & 904 & $66.1 \%$ & 463 & $33.9 \%$ & 1,367 & 2.0 \\
\hline
\end{tabular}




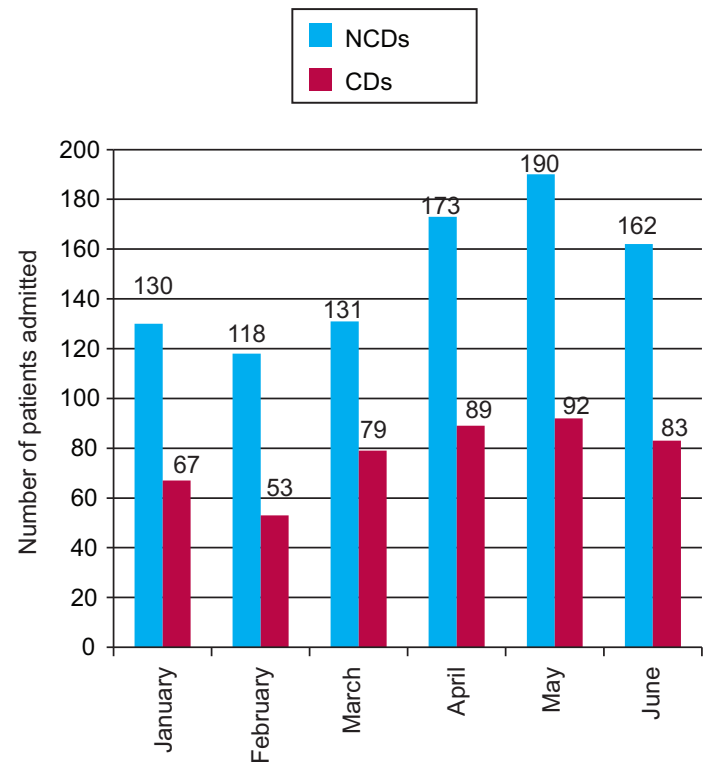

Fig.-1: Comparison of admissions due to noncommunicable and communicable diseases

There were several findings regarding the pattern of NCDs. Among the admissions due to NCDs, more than half $(51.3 \%)$ were aged between 50 to 69 years (Table-II and Figure-2). In terms of pattern of disease, cardiovascular diseases were the number one cause for hospital admission followed by endocrine disorders (Figure-3).

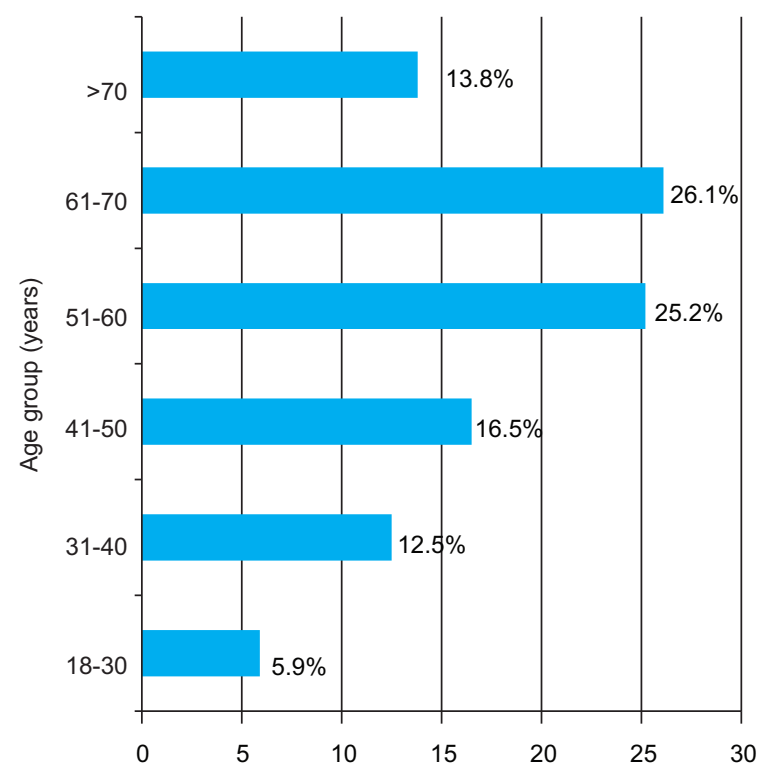

Fig.-2: Percentage of patients admitted due to noncommunicable diseases by age groups

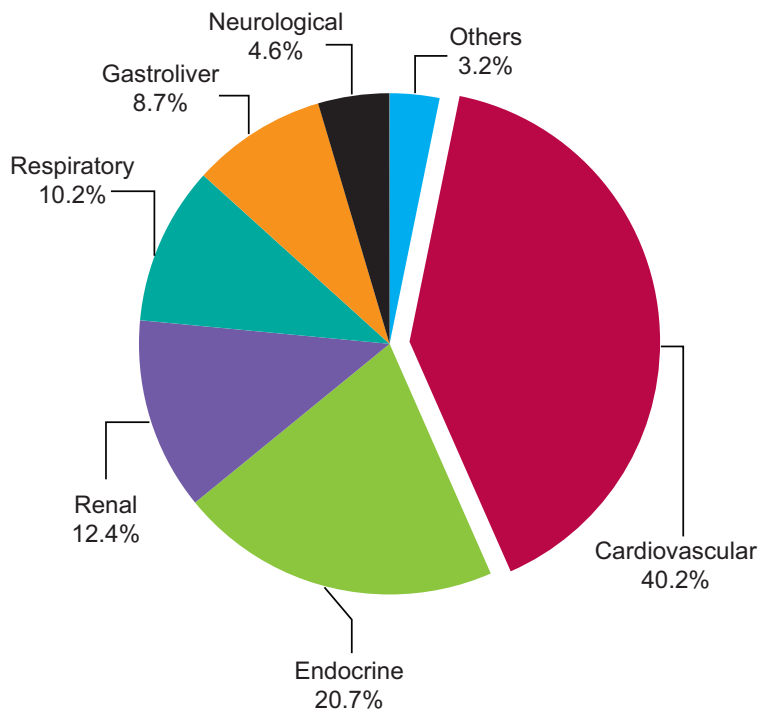

Fig.-3: Percentage of patients admitted due to types noncommunicable disease

\section{Discussion:}

This single-center, retrospective study found that NCDs account for $66.1 \%$ of total admissions and the number of cases of NCDs was two times more compared to CDs (ratio 2:1). A number of studies performed in low and middle income countries have also reported similar findings ${ }^{7-11}$. Kujur et. al. reported $56.5 \%$ admission cases due to NCDs in a tertiary care hospital of Ranchi, Jharkhand, India ${ }^{7}$. Whereas, Ogunmola et. al. found $68.4 \%$ NCDs admissions in the medical wards of a tertiary health center in a rural community of Ekiti State, Nigeria ${ }^{8}$. Excessive tobacco use,low intake of fruits and vegetables, physical inactivity,obesity, hypertension, high blood glucose, dyslipidemia all these factor are creating this huge burden of NCDs either isolated or in combination.

Advancing age is a strong non modifiable risk factor for most NCDs. In our study, more than half $(51.3 \%)$ of admitted NCD patients were aged between 50 to 70 years. One study performed in Faridpur Medical College Hospital by Tarafder BK et al. also revealed similar findings ${ }^{12}$. So, the combination of longer lives and greater burden of NCDs is demanding new schemes and policy to mitigate the upcoming outbreak.

Cardiovascular diseases were the largest contributor to NCDs in this study accounting for $40.2 \%$ of all the NCDs reported. Endocrine and renal diseases together constituted about a third of all NCDs in this study. Previously, Akubudike et. el. did a retrospective study in 
the medical ward of a tertiary center in Nigeria and reported same trend ${ }^{13}$. Again, evidences show that the detection and treatment rate of DM and HTN is inadequate among bangladeshi population.$^{14}$ So lack of awareness may contribute to this huge statistical data.

This study has some limitations. Notably, this is a singlecenter study and performed in an Upazila level hospital. So the results can not be generalized to the whole population of Bangladesh. The tenure of the study was also limited and as it was a retrospective study, there might be some patient selection bias. So Nationwide and large-scale studies are required to obtain more information regarding this matter.

\section{Conclusion:}

NCDs diseases account for significant cause of admissions in Upazila Health Complex, Chhagalnaiya, Feni and it appears to have an upward trend. Cardiovascular, endocrine and renal systems are the most affected systems. Though this study is a snapshot of NCDs, these findings could be useful to draw the attention of health authorities to adopt preventive strategies against NCDs even at Upazila level.

\section{Acknowledgement:}

We are very much grateful to Ms Rubina Akter and Ms Rahima Akter, SSN,UHC,Chhagalnaiya for their enormous support despites of all shortcomings. We also our heartiest gratitude to Mr.Shauket Hossain for his convey technical support.

\section{References:}

1. Ezzati M, Pearson-Stuttard J, Bennett JE, Mathers $\mathrm{CD}$. Acting on non-communicable diseases in lowand middle-income tropical countries. Nature. 2018;559(7715):507-516.

2. World Health Organization. Key Factsheets: NonCommunicable Disease [2017]. Available at: http:/ /www.who.int/mediacentre/factsheets/fs358/en/, assessed 30 July 2019.

3. Zaman MM, Bhuiyan MR, Karim MN, Rahman MM, Akanda AW, Fernando T. Clustering of noncommunicable diseases risk factors in Bangladeshi adults: An analysis of STEPS survey 2013. BMC Public Health. 2015;15:659.

4. Rahman MS, Akter S, Abe SK, Islam MR, Mondal $\mathrm{MN}$, Rahman JA, et al. Awareness, treatment, and control of diabetes in Bangladesh: a nationwide population-based study. PLoS One. 2015;10(2): e0118365.
5. Islam FM, Bhuiyan A, Chakrabarti R, Rahman MA, Kanagasingam $\mathrm{Y}$, Hiller JE. Undiagnosed hypertension in a rural district in Bangladesh: The Bangladesh Population-based Diabetes and Eye Study (BPDES). J Hum Hypertens. 2016;30(4): 252-259.

6. Zaman MM, Rahman MM, Rahman MR, Bhuiyan MR, Karim MN, Chowdhury MA. Prevalence of risk factors for non-communicable diseases in Bangladesh: Results from STEPS survey 2010. Indian J Public Health. 2016;60(1):17-25.

7. Kujur M, Kiran A, Kumar M. Pattern of NonCommunicable Diseases in Patients Attending Medicine OPD at a Tertiary Care Hospital of Ranchi, Jharkhand. Journal of Evolution of Medical and Dental Sciences 2015;4(27):4676-4681.

8. Ogunmola OJ, Oladosu OY. Pattern and outcome of admissions in the medical wards of a tertiary health center in a rural community of Ekiti State, Nigeria. Ann Afr Med. 2014;13(4):195-203.

9. Wachukwu CM, Emem-Chioma PC, Wokoma FS, Oko-Jaja RI. Pattern and outcome of renal admissions at the University of Port Harcourt Teaching Hospital, Nigeria: A 4 years review. Ann Afr Med. 2016;15(2):63-68.

10. Misganaw A, Mariam DH, Ali A, Araya T. Epidemiology of major non-communicable diseases in Ethiopia: a systematic review. J Health Popul Nutr. 2014;32(1):1-13.

11. Abegunde DO, Mathers CD, Adam T, Ortegon M, Strong K. The burden and costs of chronic diseases in low-income and middle-income countries. Lancet 2007:370:1929-1938.

12. Tarafder BK, Hossain AM, Sarker KD, Podder PK. Mortality burden of non-communicable Disease - a retrospective study in a tertiary Care hospital of Bangladesh. Bangladesh Journal of Medicine 2016;27:22-26.

13. Akubudike AC, Eze NC. Non Communicable Disease Admissions in Developing Country as Experienced from the Medical Ward of a Tertiary Centre in Nigeria. Central African Journal of Public Health 2018;4(2):34-37

14. Rahman MS, Akter S, Abe SK, Islam MR, Mondal MNI, Rahman JAMS, et al. Awarenes, Treatment and Control of Diabetes in Bangladesh: A Nationwide Population Based Study.PLoS One 2015; 10(2):e0118365. doi:10.1371/journale. 0118365 